\title{
Singing the body electric: Real-time and virtual performance
}

\author{
Marc Duby \\ UnIVERSITY OF SOUTH Africa
}

\begin{abstract}
Bruce Cassidy's Body Electric appeared briefly in the 1990s in Johannesburg to perform a number of concerts there, including two concerts at the University of the Witwatersrand. Led by the Canadian-born Cassidy and formed as a "healing band", the free improvising Body Electric drew on the experience and attitudes of musicians from fairly eclectic backgrounds (the late David Hoenigsberg, a Western art music composer, as well as more ostensibly "jazz" improvisers like Rashid Lanie, Rob Watson, and myself). Examining extracts (posted by Cassidy on YouTube) from Seth Asch's documentary film on the Body Electric's April 1993 performance at the University of the Witwatersrand's Bozzoli Pavilion raises questions around the legacy of exploratory music of this kind. Considering the differences between the original live performance and its current digitised state as historical record, the question arises as to whether and how these performances may be compared to one another.
\end{abstract}

KEYwORDs: Body Electric; Cassidy; embodiment; free improvisation; phenomenology.

The challenge facing the human science researcher is to describe things in themselves, to permit what is before one to enter consciousness and be understood in its meanings and essences in the light of intuition and self-reflection. (Moustakas 1994, p. 27)

Situating popular musics: IASPM 16th International Conference Proceedings, pp. 103-110 


\section{INTRODUCTION}

Bruce Cassidy lived in South Africa from 1981 until 2003, whereupon he returned to his native Canada. A member of the jazz-fusion group Blood, Sweat and Tears from 1979 to 1980, he plays trumpet and flugelhorn as well as the Electronic Valve Instrument (EVI), an electronic MIDI-based trumpet synthesizer interface invented by Nile Steiner (Patchman Music n.d.). During the 1990s Cassidy formed an ensemble called the Body Electric, which performed a number of concerts in Johannesburg, including two concerts at the University of the Witwatersrand.

The group comprised Cassidy (brass and EVI), David Hoenigsberg and Rashid Lanie (keyboards), and a rhythm section of Rob Watson (drums) and myself (bass guitar and keyboards). The musical focus of the ensemble was twofold: in addition to extensive sections of freely improvised music, we also played Cassidy's transcriptions based on devotional music. The documentary film-maker Seth Asch recorded the rehearsals and filmed the April 1993 concert at the Bozzoli Hall at Wits. My aim in this paper is to explore grounds for comparison between the original live performance and the digitised YouTube version.

\section{Free AND COLLECTIVE IMPROVISATION}

In South African jazz history, there has been a relatively small number of ensembles that have set out deliberately to explore free improvisation ${ }^{1}$. This approach to improvising is a far cry from what Gary Patrick characterises as "the group-improvisation methodology of Dixieland" in his 2004 review of Weather Report's reissued CD I sing the body electric. In the Dixieland style, there exists an underlying melodic/ harmonic schema which determines and limits the note choices available to improvisers. In contrast, free improvisation presupposes the abandonment of such schemas from the outset - temporary frameworks of this kind may or may not emerge during the course of the performance.

Further, in Dixieland, the roles of the front-line improvisers as well as the rhythm section refer to the common practice of the style period in question, and there is little room for deviation from this if one wishes to maintain the idiomatically appropriate characteristics of the genre.

In the Body Electric, the group performed a mixed repertoire of completely unscripted free compositions and Cassidy's original compositions drawing from various devotional musics from the Hindu and Buddhist traditions (in keeping with Cassidy's conception of the group as his "healing band"). "The Creation", as performed at the Bozzoli auditorium in 1993, typifies this latter category of material, in which there is no notated music and the composition unfolds in real time as a creative collaboration.

My recollection of playing Cassidy's material in the concert was that it demanded a high degree of concentration and listening, but that, in informal discussions immediately after the performance, we all felt that it had been successful and energizing and - in short - "worth the effort". It is debatable whether these positive feelings were a result of the musical content of what we had performed (especially in the 
context of the devotional music) or whether they were grounded in the attainment of what R. Keith Sawyer $(2007 ; 1997)$ has defined as group flow ${ }^{2}$. Certainly there seemed to be consensus among us that our engagement had been a liberating experience, an opinion shared by some of the audience members in conversations after the concert.

It was felt that we had successfully negotiated the kind of musical space that Wayne Bowman (1998, p. 273) describes in this statement: "Musical space is a field of action, and the human body our instrument of musical comprehension".

\section{The ELECTRONIC VALVE INSTRUMENT (EVI)}

For much of the concert, Cassidy played the Electronic Valve Instrument (EVI), invented by Nyle Steiner. The EVI is an electronic wind controller which generates MIDI data such as pitch, volume, vibrato, and so on. Designed to be connected to a synthesizer for sound production, it is capable of producing a theoretically infinite variety of timbres and has a far wider range of available notes than its acoustic counterpart, the trumpet. The only truly acoustic instrument in the concert was Rob Watson's drum kit, since there were three keyboardists in the persons of Hoenigsberg, Lanie and myself ${ }^{3}$. For Tia DeNora (2000, p. 102), Cassidy's EVI might well be defined as a form of prosthetic technology:

Prosthetic technologies are materials that extend what the body can do - for example, steam shovels, stilts, microscopes or amplification systems enhance and transform the capacities of arms, legs, eyes and voices. Through the creation and use of such technologies actors (bodies) are enabled and empowered, their capacities are enhanced. With such technologies, actors can do things that cannot be done independently; they are capacitated in and through their ability to appropriate what such technologies afford.

While DeNora's view of technology seems overwhelmingly positive (she uses terms like "enhance", "enable", and "empower"), it is worth noting that such specialised technologies (in our case, microphones, synthesizers, and amplifiers) depend on electricity for their functioning, and consequently much of the band's "empowerment" originated from the local electricity supplier. In the event of a power failure, the band would have been silent, apart from Watson's acoustic drums. In fact, the very existence of this band (and the whole phenomenon of popular music) grew out of twentieth-century technologies, since until the advent of modern amplification and synthesis techniques, none of the kinds of sonic possibilities offered by such technologies had been available.

\section{The Body Electric: What's in a NAMe?}

Cassidy's choice of name for the group seems to resonate with various other instances of this term in literature and music - perhaps most immediately with Walt 
Whitman's 1855 poem I sing the body electric ${ }^{4}$. A further resonance (and no doubt one that Cassidy would have been aware of) is with the 1972 Weather Report recording I sing the body electric. The original album cover, portraying a transparent post-human cyborg, seems to owe more to Ray Bradbury's 1969 science fiction collection of the same name than to Whitman's original poem.

Figure 1: Weather Report, I sing the body electric (Columbia 1972).

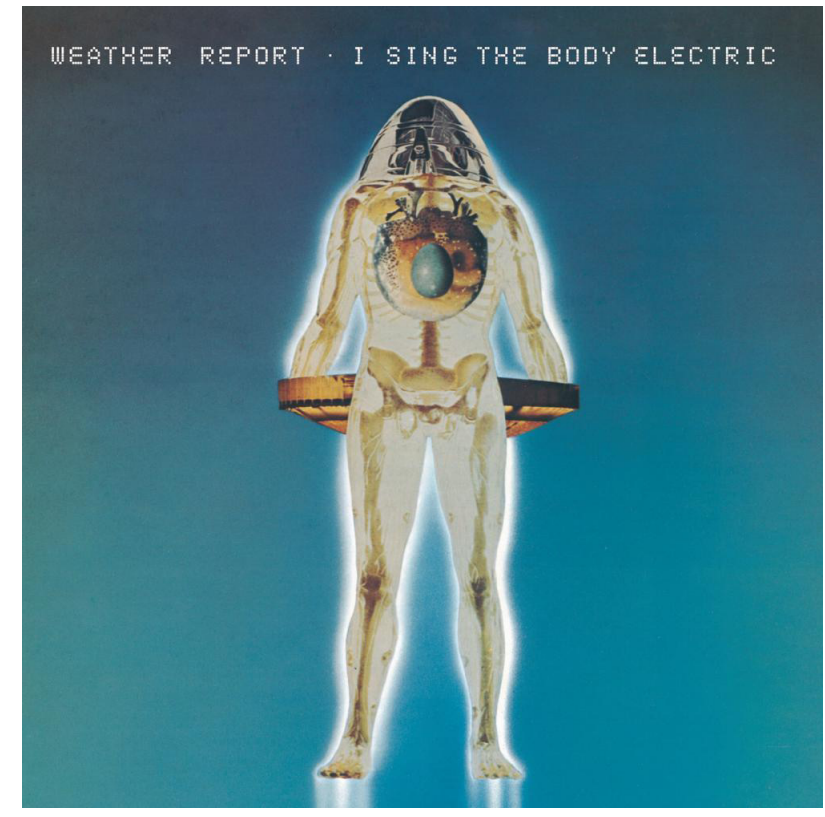

In choosing the name Body Electric, Cassidy seems not only to emphasise its intertextual character but also seems to make a statement of intent about the nature of the music, namely, that it depends on, and revels in, the new sonic possibilities offered by "post-acoustic" instruments based on twentieth-century synthesizers. In the course of researching this article, however, it became apparent that Cassidy's choice of name for the group had little or nothing to do with these tempting literary and musical connections ${ }^{5}$. In his own words, the name came directly from his experiences in meditation:

The Body Electric is a term that I had heard and used it to 'poet-ify' the group title. I was put up to the idea of using music for healing by my yoga instructor (guru). I told him, when he suggested it, that I knew nothing about healing. He said: 'Oh, your job is not to heal but to watch'. This was a very interesting and powerful statement to me because it removed ego involvement. The 'trick' was to use Sanskrit chants internally to calm and abstract the mind and then to play intuitively. (Cassidy 2011) 


\title{
Phenomenology and Semiotics: The body AND the SIGN
}

In Music as heard, Thomas Clifton (1982) presents an account of the philosophical possibilities of the phenomenological project for musical understanding ${ }^{6}$. Clifton's description of "the theoretical act" of observing music implies in the first place an understanding subject "located in a definite place and time":

\begin{abstract}
Where phenomenology can contribute most to reflective procedures in music theory is in the awareness that the properties of an object are not fixed 'in some metaphysical heaven', as Merleau-Ponty writes, but are experienced by a person located in a definite place and time. This means that the theoretical act will consist not only of observing the music, but also of observing the self observing the music. (ibid., p. 37)
\end{abstract}

It is the memory of this specific sense of place and time that informs my reading of the original concert performance, from my (inter)subjective vantage point as one of the performers. As performer, one's engagement with the musical materials as they unfold is realised in the first instance through bodily interactions with the instrument, causing it to sound and thereby bringing the music into existence.

With these thoughts in mind, I turn to examining the filmed version of the concert. I consider this performance in the light of Kevin Korsyn's (2003, p. 143) conception of the subject as constituted by media - and especially signs:
Nowadays the signifiers, images, and fantasies that compose the subject circu- late through media, particularly as the post-industrial economy revolves more and more around the consumption of signs. In seeking to obey the motto of the Delphic Oracle - 'Know thyself!' - we must recognise that modern media have transformed both the means of knowledge and the self under examination.

For Sokolowski (2000, p. 3), current technology generates appearances "not only by words spoken or written by one person to another, but by microphones, telephones, movies, and television, as well as by computers and the Internet, and by propaganda and advertising". This transformation of the subject for Sokolowski is aided and abetted by some of the self-same technologies DeNora considers as liberating. The Internet might be understood as contributing to the creation of globally distributed temporary communities of fans participating in iconic virtual imagery (Korsyn's "signifiers, images, and fantasies" par excellence). It requires a major stretch of the imagination, in my view, to equate this virtual audience with a real one, or to compare a live performance with a recording. As Sokolowski (ibid., p. 29) states:

It is interesting to note that a recording of a piece of music is different from a live performance because the recording captures just one of the performances, whereas each live performance is different from all the others. [...] When a recording captures just one performance, it is as though a movie captured just 
one aspect of a cube and only let me see that particular manifestation of the cube itself.

Perhaps the most immediate way of comparing the real and virtual instances of the same performance is in tabular form, as follows (see Table 1).

Table 1: "The Creation" (Live performance vs. YouTube version).

\begin{tabular}{|l|l|}
\hline LIVE PERFORMANCE (APRIL 1993) & YOUTUBE VERSION \\
\hline Once-off & Infinitely repeatable \\
\hline Specific time and place & Everywhere and nowhere \\
\hline Flesh and blood & Bits and bytes \\
\hline Embodied & Disembodied \\
\hline Performer's perspective & Director's perspective \\
\hline Social space & Cyberspace \\
\hline Improvised ("online") & Edited ("offline") \\
\hline Presentation & Representation \\
\hline
\end{tabular}

While these apparently antagonistic categories might seem to speak for themselves, I would like to emphasise that what I describe as the social space of the original live performance is not that of a fixed set of relationships, but the space of a temporary community brought into being in a particular place and time by circumstances. It is not necessarily a unified social space, simply concluded from the fact that not everyone in the audience might have unequivocally liked the music, or agreed with Cassidy's healing intent. In Cassidy's (2011) own words: "Unfortunately music has become so ubiquitous that it is hard to escape and it rarely gets the same degree of attention from the listener that it did when it was only experienced in a live performance situation. Recording has been a mixed blessing".

Nonetheless, this was a fraught moment in South African political history, on the eve of the country's first-ever democratic elections, and there was a mixture of fear and excitement in the air. Depending on one's particular political outlook, the country was poised on the verge of greatness, or on a slippery slope to disaster. 
Perhaps Cassidy's idea of a healing band was exactly appropriate at that particularly turbulent time in South African history.

\section{ACKNOWLEDGEMENTS}

I would like to express my gratitude to the organisers of the 16th biennial IASPM conference at which I presented the initial version of this paper. My thanks also go to my departmental colleagues George King and Annemie Stimie at Unisa, as well as to Pekka Toivanen and students at the University of Jyväskylä, Finland.

I would also especially like to acknowledge the generous contribution of time and energy made by Bruce Cassidy in helping me bring this article to fruition.

This material is based upon work supported financially by the National Research Foundation. Any opinion, findings and conclusions or recommendations expressed in this material are those of the author(s) and therefore the NRF does not accept any liability thereto.

\section{ENDNOTES}

1. Various groups led by Merton Barrow (in 1970s Cape Town), Carlo Mombelli's Prisoners of Strange (contemporary, Johannesburg), and the Body Electric come to mind. The members of Chris McGregor's Brotherhood of Breath, some of whom later were to embrace free improvisation, were forced into exile by the political circumstances of 1960 s South Africa. 2. Sawyer (1997, p. 43) defines flow as "a mental state associated with moments of highly creative activity".

3. Despite my instrument of choice being bass guitar or double bass, I chose to play keyboards to challenge myself to avoid playing habitually ingrained patterns as I found I was doing during the initial rehearsal period.

4. From Huck Gutman's (1998) analysis of the poem: "Almost at the outset Whitman acknowledges that many have doubts about the body - doubts originating in the enduring Christian notion that the body is different from the soul, and is the seat of the soul's corruption".

5. As Cassidy (2011) describes it: "This title had nothing to do with Walt Whitman or the band Weather Report but developed out of meditation experience of the 'electrical body'. The entire universe is vibrating and what we call electricity is just one form of that. Any meditator can feel directly what a scientist points to. Proceeding from gross to subtle: if you sit quietly and observe your body you can feel many forms of vibration. Breathing is a vibration (rhythm); heartbeat can soon be felt to shake the torso. Tingling (a clear manifestation of the electrical body) then can be felt, usually in the face and hands first, then the whole body. Soon the demarcation of the body from the surroundings starts to evaporate and you can feel the environment. There are many other subtle forms of vibrations and sounds and lights that subsequently arise but this is enough to illustrate that we are immersed in a sea of vibration and through it we communicate".

6. I use the fairly informal term "musical understanding" all-inclusively, attempting thereby to encompass a variety of perspectives (performer, listener, composer, consumer) and 
categories of engagement with music (cognition, perception, reflection, analysis, and so on).

\section{REFERENCES}

Bowman, Wayne D. 1998. Philosophical perspectives on music. Oxford University Press, Oxford.

Bradbury, Ray. 1969. I sing the body electric! Stories by Ray Bradbury. Knopf, New York, NY.

Cassidy, Bruce. n.d. "Body Electric at the Bazzoli - The Creation - part 1". <http://www. youtube.com/watch?v=odD6kdpjxSc\&feature=related $>$; accessed: 15.jan.10. Video.

Cassidy, Bruce. n.d. "Body Electric at the Bazzoli - The Creation part 2". <http://www. youtube.com/watch?v=7dqtv9GRMK4\&NR=1>; accessed: 15 .jan.10. Video.

Cassidy, Bruce. 2011. E-mail communication with the author, 23 July.

Clifton, Thomas. 1983. Music as heard: A study in applied phenomenology. Yale University Press, New Haven, MA.

DeNora, Tia. 2000. Music in everyday life. Cambridge University Press, Cambridge.

Gary, Patrick. 2004. "Weather Report: I sing the body electric". Jazz CD reviews, April, MusicWeb, UK. <http://www.musicweb-international.com/jazz/2004/Apr04/ weather_electric.htm>; accessed: 15.jun.11.

Gutman, Huck. 1998. "I Sing the body electric [1885]". The Walt Whitman Archive. <http://www.whitmanarchive.org/criticism/current/encyclopedia/entry_9.html>; accessed: 15.jun. 11.

Korsyn, Kevin. 2003. Decentering music: A critique of contemporary musical research. Oxford University Press, Oxford.

Moustakas, Clark. 1994. Phenomenological research methods. SAGE Publications, Thousand Oaks, CA.

Patchman Music. n.d. "The Nyle Steiner homepage". <http://www.patchmanmusic.com/ NyleSteinerHomepage.html>; accessed: 15.jun.11.

Sawyer, R. Keith (ed.). 1997. Creativity in performance. Ablex Publishing Corporation, Greenwich, CT.

Sawyer, R. Keith. 2007. Group genius: The creative power of collaboration. Basic Books, New York, NY.

Sokolowski, Robert. 2000. Introduction to phenomenology. Cambridge University Press, Cambridge.

Weather Report. 1972. I sing the body electric. Columbia KC 31352, United States. Phonogram. 